\title{
Adenoid Cystic Carcinoma ex Pleomorphic Adenoma of the Parotid Gland
}

\author{
Fumio Ide $\cdot$ Kenji Mishima $\cdot$ Hiroyuki Yamada \\ Ichiro Saito
}

Received: 12 November 2008 / Accepted: 6 February 2009/Published online: 28 February 2009

(C) Humana 2009

\begin{abstract}
There is a considerable variation in the histologic subtype of epithelial malignancies among carcinoma ex pleomorphic adenomas (CXPA) and virtually any known carcinoma entity can develop. To our knowledge, adenoid cystic carcinoma (AdCC) ex PA is quite rare despite the fact that de novo AdCC is the fourth most common salivary gland malignancy. We describe a new case of AdCC ex PA in the parotid gland of a 62 year-old woman. In our patient, there was a short interval of time between parotidectomy and local recurrence and rapid development of distant metastases. Although most of the reported cases are considered low-grade, evidence is presented here that AdCC can take the form of a high-grade malignancy in PA.
\end{abstract}

Keywords Adenoid cystic carcinoma .

Carcinoma ex pleomorphic adenoma .

High-grade malignancy · Parotid gland

\section{Introduction}

Carcinoma ex pleomorphic adenoma (CXPA), as a group, constitutes $12 \%$ of malignant salivary gland tumors [1], and in data from the Armed Forces Institute of Pathology, this ranks it as the sixth most common carcinoma at this location [2]. Of all PA, CXPA accounts for 9.5\% [2], and has been noted ab initio or at recurrence [1-3]. Although there is no prototypical carcinoma entity, the forms of

F. Ide $(\bowtie) \cdot$ K. Mishima $\cdot$ H. Yamada $\cdot$ I. Saito

Department of Pathology, Tsurumi University School of Dental

Medicine, 2-1-3 Tsurumi, Tsurumi-ku, Yokohama 230-8501,

Japan

e-mail: ide-f@tsurumi-u.ac.jp malignancy found are most common adenocarcinoma not other wise specified, salivary duct carcinoma and undifferentiated carcinoma [1-7]. The malignant component is often difficult to subclassify as one of exactly defined carcinoma categories [6], and more than one phenotype may be present $[5,8]$.

In previous large series [5-12], the cribriform growth pattern considered supportive of a diagnosis of adenoid cystic carcinoma (AdCC) was observed in $4-33 \%$ of CXPA, many of which comprised only a limited portion of poorly differentiated adenocarcinoma $[5,11]$. Of six reports, four lacked illustrations of the AdCC component [5-7, 12], and only two involved histopathologic findings of AdCC ex PA with no information of the individual case $[8,11]$. In the study of Moberger and Eneroth [10], a single convincing example was detailed and the same case was also briefly described in the paper of Eneroth et al. [9]. Our literature search disclosed six additional cases of pure AdCC ex PA described by name [13-17]. The following is a rare emergence of AdCC from a primary PA in the parotid gland which pursued an unpredictable aggressiveness on behavioral basis.

\section{Case Report}

A 62 year-old woman presented with an 8 month history of a painless mass of the right parotid gland. With magnetic resonance imaging and computed tomography (Fig. 1), a well-circumscribed, $4 \mathrm{~cm}$ tumor with evidence of calcification was found in the deep lobe and diagnosed at Stage II $\left(\mathrm{T}_{3} \mathrm{~N}_{0} \mathrm{M}_{0}\right)$. She had no clinically detectable tumor in any other site and her past medical history was non-contributory. Following the histologic diagnosis of CXPA in the initial parotidectomy specimen, the definitive surgery with 


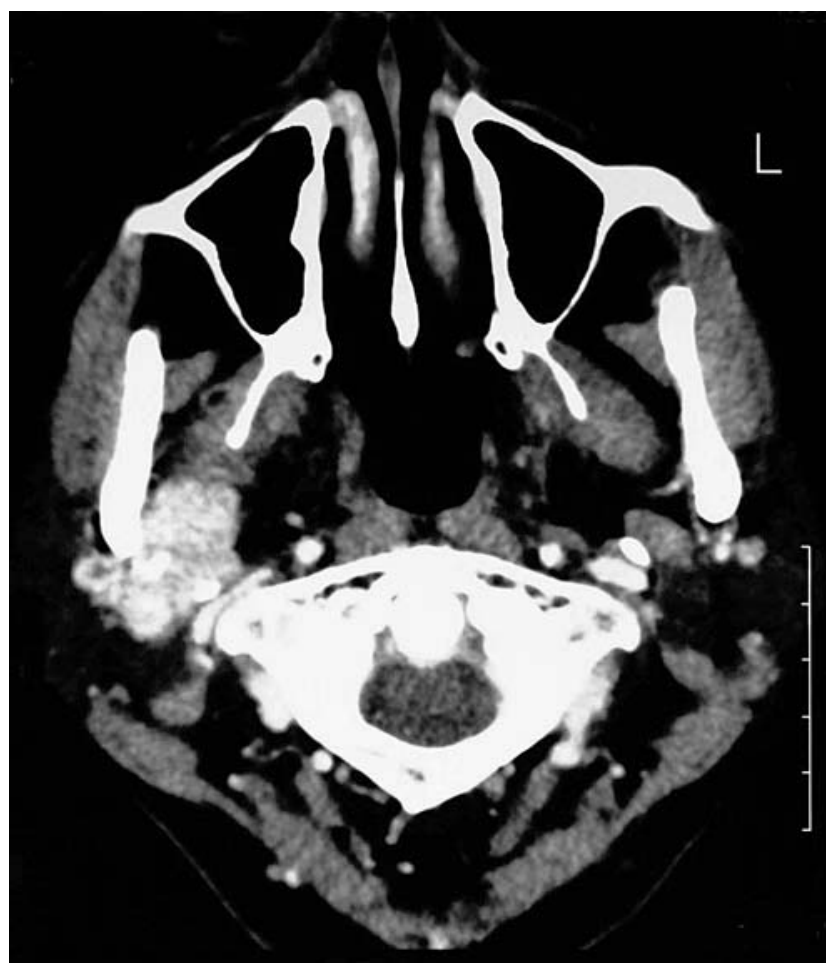

Fig. 1 Computed tomography scan shows a heterogeneously enhanced and well-circumscribed tumor of the right parotid gland

dissection of parapharyngeal area and upper neck was completed one month later. Microscopically, there was neither residual carcinoma nor positive cervical lymph node. Nineteen months postoperatively, local recurrence was noted in the posterior pharyngeal wall and small metastatic foci in the lung and liver were diagnosed on the basis of computed tomography and magnetic resonance imaging. At the patient's wish, both lesions were not biopsied and only chemotherapy was carried out at another institution. Although specific details of protocols were not available, she still has evidence of disease two years later.

Macroscopically, the bilobed mass measuring $4 \times 4 \times$ $3 \mathrm{~cm}^{3}$ appeared deceptively well-demarcated and on cut surface, contained a large solid nodule with hemorrhage and smaller foci with sclerosis. On microscopic examination, the tumor was found to be not excised with clear margins (Fig. 2a). It was composed of two strikingly contrasting types of tumor; lobulated aggregates of AdCC and densely hyalinized nodules of PA, with the former constituting $>80 \%$ of lesion (Fig. 2a, b). The remnants of PA were recognizable by the bilayered ductal structures in the desmoplastic, calcified or ossified stroma (Fig. 2c, d). Solid and cribriform growth patterns occurred together in the AdCC component; tumor cell necrosis including comedo-type was readily apparent in the former and excessive basal lamina was characteristically evident in the latter (Fig. 2e, f). The nuclei of basaloid carcinoma cells were angular and showed moderate mitotic rate and mild to moderate atypia (Fig. 2g). In the AdCC areas, neural invasion was common, but there was no vascular involvement. Because the solid pattern represented more than $40 \%$ of carcinoma, the AdCC element was categorized into Grade III [18, 19]. Even in multiple sampling, the transition between PA and AdCC was difficult to trace because of hypocellularity and hyalinization of the PA component. The coexistence of another high-grade carcinoma or carcinosarcoma was not evident.

\section{Discussion}

Among seven cases of AdCC ex PA with sufficient data [10, 13-17], five tumors arose in association with a primary PA including a long-standing ( $>50$ years) lesion [13-16], whereas the remaining two developed as a recurrent tumor at the site of a previously excised PA [10, 17]. It is acknowledged that PA and AdCC are composed of variable proportions of ductal and myoepithelial type cells [19-22]. Considering the immunohistochemical result that $19 \%$ of supervening carcinoma in CXPA shows the bidirectional line of differentiation into ductal and myoepithelial cells [21, 23], the sequential evolution of PA to AdCC may not be surprising. Circumstantial evidence also comes from cases of PA showing AdCC-like phenotypic manifestations [22, 24]. Conversely, the diagnostic consideration of in situ or intracapsular AdCC within PA should be given in such tumors [7, 9, 11, 13, 24]. The cribriform nests in PA are usually limited to small areas and their nuclear features are not hyperchromatic, angular as in the case of AdCC [20, 22].

Conceptually, salivary tumors that occupy a single gland and consisted of two distinct types may be categolized as either synchronous or hybrid [19]. There were only a few reports on simultaneous occurrence of PA and adenocarcinoma; the latter included acinic cell adenocarcinoma, mucoepidermoid carcinoma and salivary duct carcinoma only [25]. An unusual combination of myoepithelioma of spindle cell variant and AdCC of cribriform type was also described [26]. Importantly, synchronous tumors never demonstrate a confluence between two separable entities as seen in CXPA [25]. It is our understanding that hybrid lesions show transitional areas between two histologically different tumors in a single mass, suggesting their clonal origin [27]. This rare condition can be seen as a combination of hybrid adenomas, hybrid carcinomas or carcinoma with adenoma [19] and the most commonly reported partner of AdCC was salivary duct carcinoma and epithelial-myoepithelial carcinoma [27]. In contrast to CXPA, hybrid tumors are usually characterized by the mixture of two well-defined carcinomas [27], and hybrids exhibiting both benign and malignant components are 


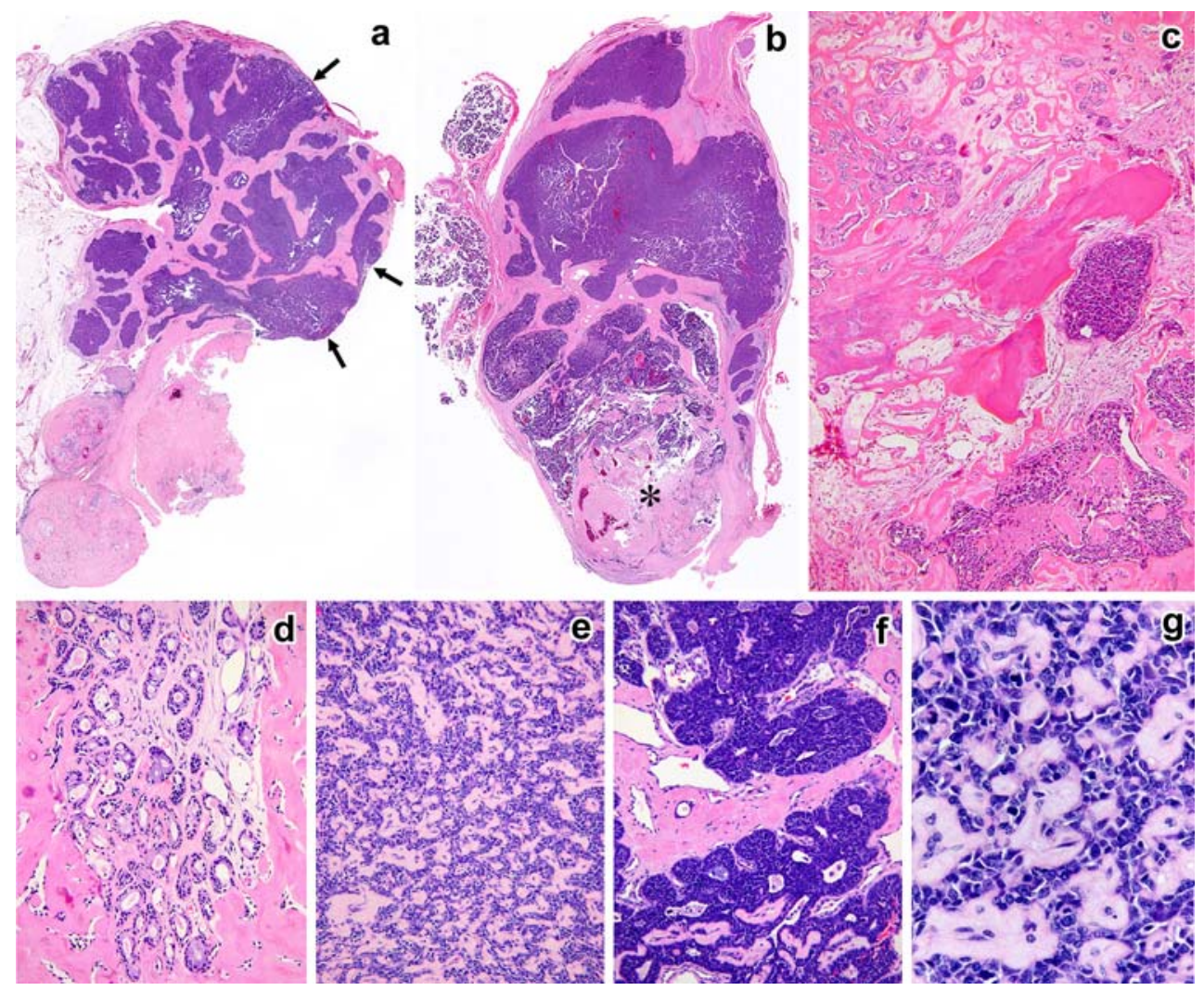

Fig. 2 (a) Scar-like discrete foci of pleomorphic adenoma (PA) and multilobulated nodule of adenoid cystic carcinoma (AdCC) are juxtaposed to each other without a transitional zone. Arrows indicate positive surgical margins, (b) PA (asterisk) and AdCC are blending each other in another section, (c) woven bone trabeculae are present between residual PA (upper) and solid nests of AdCC with

exceptional, with a sole combination of basal cell adenoma and AdCC [19].

One of the important pathologic factors associated with patient prognosis in AdCC includes tumor grade [18-20, 28]. Unfortunately, the universally accepted grading system for de novo AdCC, i.e., the proportion of the tumor with a solid pattern, has not yet been used in any case of AdCC ex PA. Judging from the photomicrographs and/or descriptions, most of the previously reported cases of AdCC ex PA were low-grade $[6,8,11,13-15,17]$. The present AdCC component was regarded as Grade III and the solid growth pattern was predominant in two remaining cases that developed metastasis $[9,16]$. In de novo AdCC, distant metastasis frequently occurs without regional lymph node involvement, even after local control of tumor [20,28]. Given that two of three cases with metastatic spread had negative cervical nodes [15, 16], AdCC ex PA is certainly no exception; notably, two patients represented skin metastasis that is very rare in de novo AdCC $[9,15]$. In the present high-grade case, clinical signs of local recurrences and distant metastases were evinced within 19 months on follow-up imaging; comedonecrosis (lower), (d) nidus of unmistakable PA surrounded by sclerotic stroma, (e) intercellular basal lamina material is conspicuous within cribriform areas, (f) small pseudocystic and ductal spaces are filled with necrotic debris, (g) nuclei of carcinoma cells are hyperchromatic, angular and irregular shaped (HematoxylinEosin, $\mathbf{a}$ and $\mathbf{b}, \times 3 ; \mathbf{c}, \times 40 ; \mathbf{d}, \mathbf{e}$, and $\mathbf{f}, \times 200 ; \mathbf{g}, \times 400)$

nevertheless, our patient is alive with disease two years postoperatively. This is in keeping with the fact that some of patients with de novo AdCC pursue prolonged survivals despite distant metastasis [28].

\section{References}

1. Gnepp DR, Brandwein-Gensler MS, El-Naggar AK, Nagao T. Carcinoma ex pleomorphic adenoma. In: Barnes L, Eveson JW, Reichart P, Sidransky D, editors. Pathology and genetics of head and neck tumours. Lyon: IARC Press; 2005. p. 242-3.

2. Ellis GL, Auclair PL. Tumors of the salivary glands, vol. 4. Washington, DC: American Registry of Pathology and Armed Forces Institute of Pathology; 2008. p. 259-68.

3. Tortoledo ME, Luna MA, Batsakis JG. Carcinomas ex pleomorphic adenoma and malignant mixed tumors. Histomorphologic indexes. Arch Otolaryngol. 1984;110:172-6.

4. Gnepp DR. Malignant mixed tumors of the salivary glands: a review. Pathol Annu. 1993;28:279-328.

5. Rosa JC, Fonseca I, Felix A, Soares J. Immunohistochemical study of c-erbB-2 expression in carcinoma ex-pleomorphic adenoma. Histopathology. 1996;28:247-52. doi:10.1046/j.1365-2559.1996. d01-424.x. 
6. Lewis JE, Olsen KD, Sebo TJ. Carcinoma ex pleomorphic adenoma: pathologic analysis of 73 cases. Hum Pathol. 2001;32: 596-604. doi:10.1053/hupa.2001.25000.

7. Zbaren P, Zbaren S, Caversaccio MD, Stauffer E. Carcinoma ex pleomorphic adenoma: diagnostic difficulty and outcome. Otolaryngol Head Neck Surg. 2008;138:601-5. doi:10.1016/j.otohns. 2008.01.013.

8. Spiro RH, Huvos AG, Strong EW. Malignant mixed tumor of salivary origin. A clinicopathologic study of 146 cases. Cancer. 1977;39:388-96. doi:10.1002/1097-0142(197702)39:2<388::AIDCNCR2820390204>3.0.CO;2-D.

9. Eneroth CM, Blanck C, Jakobsson PA. Carcinoma in pleomorphic adenoma of the parotid gland. Acta Otolaryngol. 1968;66: 477-92. doi:10.3109/00016486809126313.

10. Moberger JG, Eneroth CM. Malignant mixed tumors of the major salivary glands. Special reference to the histologic structure in metastases. Cancer. 1968;21:1198-211. doi:10.1002/1097-0142 (196806)21:6<1198::AID-CNCR2820210623>3.0.CO;2-Q.

11. LiVolsi VA, Perzin KH. Malignant mixed tumors arising in salivary glands. I. Carcinomas arising in benign mixed tumors: a clinicopathologic study. Cancer. 1977;39:2209-30. doi:10.1002/1097-0142 (197705)39:5<2209::AID-CNCR2820390540>3.0.CO;2-8.

12. Katori H, Nozawa A, Tsukada M. Increased expression of cyclooxygenase- 2 and $\mathrm{Ki}-67$ are associated with malignant transformation of pleomorphic adenoma. Auris Nasus Larynx. 2007;34:79-84. doi: 10.1016/j.anl.2006.09.006

13. Brocheriou C, Baudin JP, Verola O. Adenoid cystic carcinoma on pleomorphic adenoma. Report of two cases. Rev Stomatol Chir Maxillofac. 1985;86:36-40.

14. Geisinger KR, Reynolds GD, Vance RP, McGuirt WF. Adenoid cystic carcinoma arising in a pleomorphic adenoma of the parotid gland. An aspiration cytology and ultrastructural study. Acta Cytol. 1985;29:522-6.

15. Makdessian AS, Heathcote JG, Lampe HB. Cutaneous metastasis from a parotid adenoid cystic carcinoma arising in a pleomorphic adenoma. J Otolaryngol. 1999;28:166-70.

16. Freeman SR, Sloan P, de Carpentier J. Carcinoma ex-pleomorphic adenoma of the nasal septum with adenoid cystic and squamous carcinomatous differentiation. Rhinology. 2003;41:118-21.

17. Manganaris A, Kiziridou A, Manganaris T. Unusual localization of an adenoid cystic carcinoma subsequent to superficial parotidectomy for a benign lesion. J Craniofac Surg. 2007;18:231-5.
18. Szanto PA, Luna MA, Tortoledo ME, White RA. Histologic grading of adenoid cystic carcinoma of the salivary glands. Cancer. 1984;54:1062-9. doi:10.1002/1097-0142(19840915)54: $6<1062::$ AID-CNCR2820540622>3.0.CO;2-E.

19. Perez-Ordonez B. Selected topics in salivary gland tumour pathology. Curr Diagn Pathol. 2003;9:355-65. doi:10.1016/S09686053(03)00070-X.

20. Ellis GL, Auclair PL. Tumors of the salivary glands, vol. 4. Washington, DC: American Registry of Pathology and Armed Forces Institute of Pathology; 2008. p. 225-46.

21. Cheuk W, Chan JKC. Advances in salivary gland pathology. Histopathology. 2007;51:1-20. doi:10.1111/j.1365-2559.2007. 02719.x.

22. Ellis GL, Auclair PL. Tumors of the salivary glands, vol. 4. Washington, DC: American Registry of Pathology and Armed Forces Institute of Pathology; 2008. p. 49-71.

23. Altemani A, Martins MT, Freitas L, Soares F, Araujo NS, Aarujo VC. Carcinoma ex pleomorphic adenoma (CXPA): immunoprofile of the cells involved in carcinomatous progression. Histopathology. 2005;46:635-41. doi:10.1111/j.1365-2559.2005.02157.x.

24. Ogawa I, Miyauchi M, Matsuura H, Takata T. Pleomorphic adenoma with extensive adenoid cystic carcinoma-like cribriform areas of parotid gland. Pathol Int. 2003;53:30-4. doi:10.1046/ j.1440-1827.2003.01432.x.

25. Curry JL, Petruzzelli GJ, McClatchey KD, Lingen MW. Synchronous benign and malignant salivary gland tumors in ipsilateral glands: a report of two cases and a review of literature. Head Neck. 2002;24:301-6. doi:10.1002/hed.10048.

26. Hanada T, Hirase H, Ohyama M. Unusual case of myoepithelioma associated with adenoid cystic carcinoma of the parotid gland. Auris Nasus Larynx. 1995;22:65-70.

27. Nagao T, Sugano I, Ishida Y, Asoh A, Munakata S, Yamazaki K, et al. Hybrid carcinomas of the salivary glands: report of nine cases with a clinicopathologic, immunohistochemical, and p53 gene alteration analysis. Mod Pathol. 2002;15:724-33. doi:10.1097/ 01.MP.0000018977.18942.FD.

28. Sung MW, Kim KH, Kim JW, et al. Clinicopathologic predictors and impact of distant metastasis from adenoid cystic carcinoma of the head and neck. Arch Otolaryngol Head Neck Surg. 2003; 129:1193-7. doi:10.1001/archotol.129.11.1193. 